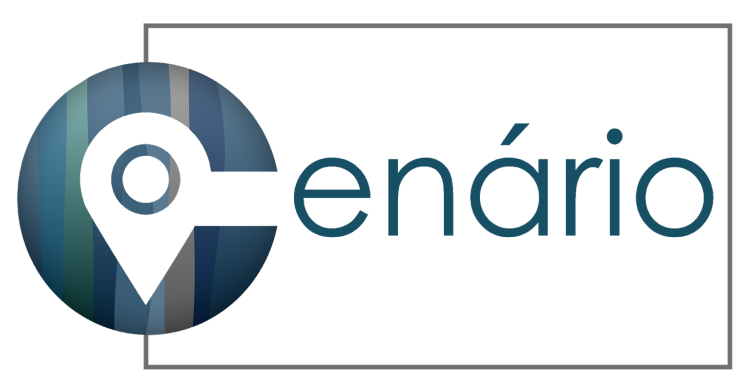

\title{
Viagens e Turismo: Emília Snethlage e Heloisa Alberto Torres as cientistas e viajantes da Amazônia do século $X^{1}$
}

\author{
Travel and Tourism: Emilia Snethlage and Heloisa Alberto Torres the \\ scientists and travelers of the 20th century Amazon
}

\author{
Viajes y turismo: Emília Snethlage y Heloisa Alberto Torres los \\ científicos y viajeros de la Amazonía del siglo XX
}

Diana Priscila Sá Alberto - Universidade Federal do Pará (UFPA).

\section{Resumo}

Palavras-clave:

Viagens;

Turismo;

Viajantes;

Turistas;

Amazônia.

\begin{abstract}
As viagens na região Amazônica trazem à tona muitas perspectivas de pesquisa em diferentes áreas do conhecimento. Estudos na História, principalmente, mostram-se como janelas para a noção desse espaço que sempre tomou conta do imaginário eurocêntrico. E o Turismo também tem buscado ampliar as investigações sobre a região, com base nas teorias das viagens. Os viajantes e naturalistas foram os principais personagens que vieram e aqui desembarcaram para escrever, pintar e estudar os componentes naturais e humanos da região. Esses viajantes, no masculino, formavam maioria. Mas, as mulheres também se fizeram presentes aqui, explorando e pesquisando a Amazônia, especificamente o Estado do Pará. A ciência foi um dos principais pilares para que a exploração da Amazônia se tornasse parte da vivência desses e dessas, talvez, "primeiros e primeiras turistas". O objetivo desta pesquisa é o de apresentar como duas cientistas, uma alemã Emília Snethlage e uma brasileira Heloísa Alberto Torres desenvolveram pesquisas na Amazônia paraense e a partir de seus estudos apontar uma possível conexão com a História do Turismo na região. Essas duas cientistas tornaram-se nomes importantes das ciências naturais e sociais, respectivamente, no Brasil e no mundo. Abordagem teórica desse artigo está construída na História da Ciência e no Turismo. Passando pelo estudo do Gênero, pois o foco são duas mulheres cientistas. A metodologia abalizada na História, onde as fontes em bibliotecas como Museu Paraense Emílio Goeldi, e em sites da Biblioteca Nacional Digital e do acervo do Arquivo Nacional do Rio de Janeiro são os objetos de análise das viagens dessas cientistas. Instrumentos utilizados são os relatórios de viagens, cartas, recortes dos jornais, publicações em que surgem as incursões dessas pesquisadoras. Dentre os principais resultados até o presente momento tem-se que as viagens dessas mulheres cientistas contaram com elementos que hoje entende-se como equipamentos turísticos, tais como: hospedagem, transportes, alimentação, redes de guias. Interessante notar como essas pesquisas
\end{abstract}

\footnotetext{
${ }^{1}$ Este artigo é procedente da tese de doutorado intitulada: EMÍLIA SNETHLAGE E HELOISA ALBERTO TORRES: Gênero e Ciência na Amazônia do século XX, e está sendo realizada no Programa de Pós-graduação em História Social da Amazônia PPHIST/IFCH/UFPA.
} 
aproximam-se de compreender como a região foi investigada por elas. E mais ainda suas cartas e relatórios apontam como essas viagens além de científicas, vislumbraram a compreensão de como a História e o Turismo podem unir-se enquanto disciplinas para se entender como a atividade turística desenvolveu-se na região amazônica.

\section{Abstract}

\section{Keywords:}

Travel;

Tourism;

Travelers:

Tourists;

Amazon.

The trips in the Amazon region bring up many perspectives of research in different areas of knowledge. Studies in history, mainly, show themselves as windows to the notion of that space that has always taken over the Eurocentric imaginary. And Tourism has also sought to expand investigations about the region, based on theories of travel. Travelers and naturalists were the main characters who came and landed here to write, paint and study the natural and human components of the region. These male travelers comprised a majority. But, women were also present here, exploring and researching the Amazon, specifically the State of Pará. Science was one of the main pillars for the exploration of the Amazon to become part of the experience of these and, perhaps, "first and first tourists". The objective of this research is to present how two scientists, a German Emília Snethlage and a Brazilian Heloísa Alberto Torres developed research in the Amazon of Pará and from their studies point out a possible connection with the History of Tourism in the region. These two scientists became important names in the natural and social sciences, respectively, in Brazil and in the world. The theoretical approach of this article is built on the History of Science and Tourism. Going through the study of Gender, as the focus is two female scientists. The methodology supported in History, where the sources in libraries such as Museu Paraense Emílio Goeldi, and in websites of the National Digital Library and the collection of the National Archives of Rio de Janeiro are the objects of analysis of the travels of these scientists. Instruments used are travel reports, letters, newspaper clippings, publications in which these researchers' incursions appear. Among the main results to date, the travels of these women scientists included elements that today are understood as tourist facilities, such as: lodging, transport, food, networks of guides. It is interesting to note how these surveys come close to understanding how the region was investigated by them. And even more so, their letters and reports show how these trips, besides being scientific, envisioned the understanding of how History and Tourism can come together as disciplines to understand how the tourist activity developed in the Amazon region.

\section{Resumen}

\section{Palabras clave:}

Viajes;

Turismo;

Viajeros;

Turistas;

Amazonas.
Os viajes en la región amazónica traen muchas perspectivas de investigación en diferentes áreas del conocimiento. Los estudios de historia, principalmente, se muestran como ventanas a la noción de ese espacio que siempre se ha apoderado del imaginario eurocéntrico. Y Turismo también ha buscado ampliar las investigaciones sobre la región, basadas en teorías de viajes. Los viajeros y naturalistas fueron los personajes principales que llegaron y aterrizaron aquí para escribir, pintar y estudiar los componentes naturales y humanos de la región. Estos viajeros masculinos constituían una mayoría. Pero, las mujeres también estuvieron presentes aquí, explorando e investigando la Amazonía, específicamente el Estado de Pará. La ciencia fue uno de los principales pilares para que la exploración de la Amazonía se convirtiera en parte de la experiencia de estas y, quizás, "primera y primera turistas ". El objetivo de esta investigación es presentar cómo dos científicos, una alemana Emília Snethlage y una brasileña Heloísa Alberto Torres desarrollaron investigaciones en la Amazonía de Pará y a partir de sus estudios señalan una posible conexión con la Historia del Turismo en la región. Estos dos científicos se convirtieron en nombres importantes en las ciencias naturales y sociales, respectivamente, en Brasil y en el mundo. El enfoque teórico de este artículo se basa en la Historia de la Ciencia y el Turismo. Pasando por el estudio de Género, ya que el enfoque son dos científicas. La metodología sustentada en Historia, donde las fuentes en bibliotecas como el Museu Paraense Emílio Goeldi, y en los sitios web de la Biblioteca Nacional Digital y la colección del Archivo Nacional de Río de Janeiro son objetos de análisis de los viajes de estos científicos. Los instrumentos utilizados son reportajes de viajes, cartas, recortes de periódicos, publicaciones en las que aparecen las incursiones de estos investigadores. Entre los principales resultados a la fecha, los viajes de estas científicas incluyeron elementos que hoy se entienden como facilidades turísticas, tales como: alojamiento, transporte, alimentación, redes de guías. Es interesante notar cómo estas encuestas se acercan a comprender cómo investigaron la región. Y más aún, sus cartas e informes muestran cómo estos viajes, además de científicos, vislumbraron la comprensión de cómo Historia y Turismo pueden confluir como disciplinas para entender cómo se desarrolló la actividad turística en la región amazónica. 
Recebido em

06/11/2020. Aprovado

em: 03/12/2020

Revisado por pares

-ISSN: 2318-8561
Como citar APA: Alberto, D. P. S. (2021). Viagens e Turismo: Emília Snethlage e Heloisa Alberto Torres as cientistas e viajantes da Amazônia do século XX. Cenário: Revista Interdisciplinar em Turismo e Território, Brasília, 9 (1), Jam./abr.. $\underline{10.26512 / \text { revistacenario.v9i1.35032 }}$

\section{Introdução}

Inicialmente é necessário alertar o leitor que as noções, interações e desdobramentos entre a História, Gênero e Turismo, juntos, surgem neste trabalho como fundamento que desencadeou uma tese de doutorado em andamento, e alinhou acontecimentos e revelou personagens. Dito isso, esclarece-se o despertar a atenção nessa tríade também permitiu aprofundar o entendimento de que os valores científicos, as dinâmicas socioespaciais e os discursos de Gênero e do Turismo delinearam trajetórias para apontar uma possível investigação da história do Turismo na Amazônia ao longo da primeira metade do século XX.

Diante dos primeiros movimentos de aproximação, ergueu-se um mosaico de questões a oferecer inquietações que necessitam ser investigadas no interesse de iluminar processos socioculturais e de convivialidades que revelem uma nova perspectiva de pensar, analisar e investigar a atividade turística. Essas possibilidades de investigar o Turismo, por meio de outros olhares tem garantido adentrar em outros espaços disciplinas, como na História e no Gênero. Disciplinas estas que têm contribuído e ainda encerram a colaborar com as investigações que envolvem o fenômeno da atividade turística.

As viagens na região Amazônica trazem à tona muitas perspectivas de pesquisa. Estudos na História, principalmente, mostram-se como janelas para o conhecimento desse espaço que sempre tomou conta do imaginário eurocêntrico. E o Turismo também tem buscado ampliar as investigações acerca da região, com base nas teorias de viagens. Viajantes e naturalistas foram os principais personagens que vieram e aqui desembarcaram para escrever, pintar e estudar os componentes naturais e humanos da região. É nesse universo que $o$ artigo a seguir principia entrar e trazer uma conotação histórica para o Turismo.

Com relação ao estudo do Gênero, pode-se sugerir que em pouco mais de 6 anos as investigações na atividade turística têm trazido o foco a partir dessa disciplina. Especificamente, ao concernente as mulheres. O campo de trabalho profissional no turismo tem sido o principal foco de análises relacionadas ao gênero. Mas, as mulheres também se fizeram presentes no campo das viagens e da ciência, explorando e pesquisando a Amazônia, especificamente o Estado do Pará. E esse movimento traz uma perspectiva para adensar o debate do gênero no turismo, vindo do estudo das viagens cientificas. A ciência foi um dos principais pilares para que o estudo da Amazônia se tornasse parte da vivência desses e dessas, talvez, "primeiros e primeiras turistas".

É mister ressaltar essa investigação como um assunto a envolver questões que estão surgindo ao longo da escrita da tese, entre elas destacam-se: por que as mulheres cientistas eram invisibilizadas nas suas trajetórias cientificas? $\mathrm{E}$ por que não se pode 
investigar a história do turismo no Brasil, por meio das viagens dessas mulheres cientistas que vieram até a Amazônia? Com base nessas indagações, procurou-se delinear para este trabalho o objetivo é o de apresentar como duas cientistas: a alemã Emília Snethlage e a brasileira Heloísa Alberto Torres, que desenvolveram pesquisas na Amazônia paraense no começo do século XX. E a partir de seus estudos apontar uma possível conexão com a História do Turismo na região amazônica. Essas duas cientistas tornaram-se nomes importantes das ciências naturais e sociais, respectivamente, no Brasil e no mundo.

A teoria apresentada para o artigo tem como fundamentos estudos na História da Ciência, do Gênero e Turismo. Eixos que vêm permeando a discussão da tese, e que fazem parte das investigações em curso. A abordagem teórica busca construir uma discussão ampla na História da Ciência e no Turismo. Passando pelo estudo do Gênero, pois o foco são duas mulheres cientistas, e assim reunir elementos que possam ser utilizados por outras pesquisas, não somente no Turismo, mas como na própria História e na Antropologia.

Como a pesquisa está sendo desenvolvida aos moldes da História, o principal campo de estudo da tese e para este trabalho são as fontes históricas. Estas são relatórios de viagens, cartas, recortes dos jornais, publicações em que surgem as incursões das viagens e do trabalho dessas pesquisadoras. Como instrumental metodológico foram feitas análises dessas fontes, por meio de leituras e construção de fichamentos. Estes organizados por pontos em comum que ligam elementos das viagens feitas por elas e interpretação para a teoria do Turismo. As fontes encontram-se, principalmente, em bibliotecas como do Museu Paraense Emílio Goeldi - MPEG, em Belém/PA. Em sites da Biblioteca Nacional Digital - BND e do acervo do Arquivo Nacional do Rio de Janeiro ANRJ. Que em virtude da pandemia de Covid $^{2}-19$ ainda não puderam ser visitados no estado do Rio de Janeiro. As fontes nesse caso são os objetos de análise das viagens dessas cientistas que ligam as teorias da História da Ciência, ao Gênero e ao Turismo. Além de referências bibliográficas de autoras e autores que escreveram sobre Emília Snethlage e Heloísa Alberto Torres.

E por fim, ressalta-se que a tese de doutorado está em andamento com dois anos de análise e já qualificada. Até o momento da escrita desse artigo a pesquisa apontou para alguns resultados preliminares. O estudo da História da Ciência, por meio das viagens e viajantes (homens e mulheres) podem oferecer subsídios teóricos importantes para o estudo da Teoria do Turismo. As viagens dessas mulheres cientistas contaram com elementos que hoje entende-se como equipamentos turísticos, tais como: hospedagem, transportes, alimentação, redes de guias. Interessante notar como essas pesquisas de campos realizadas por Emília e Heloísa aproximam-se de compreender como a região foi investigada por elas, e daí a importância do estudo da História da Ciência e do Gênero. E mais ainda, suas cartas e relatórios apontam como essas viagens além de científicas, vislumbraram a compreensão de como a História e o Turismo podem unir-se enquanto disciplinas, para se entender como a atividade turística desenvolveu-se na região amazônica.

\section{Apresentações teóricas sobre Gênero, História da Ciência e Turismo}

Categorizar e historicizar o gênero se faz oportuno para que suas aplicações sejam importantes ao pensar as diversas questões sobre como Emília Snethlage e Heloísa Alberto Torres estavam inseridas no universo masculino da ciência brasileira. Suas viagens de campo e suas relações com o masculino e com o feminino ao longo de suas carreiras cientificas. Esferas estas percebidas ao tomar conta das fontes e das referências escritas sobre as mulheres na ciência.

\footnotetext{
${ }^{2}$ Em março de 2020 foi decretado em todo território brasileiro estado de alerta pandêmico em virtude do aumento e mortes de pessoas com quadro de Síndrome Respiratória Aguda (SRAG), A COVID-19 a doença causada pelo coronavírus SARS-CoV-2 (BIOEMFOCO, 2020).
} 
Ao pensar a trajetória de mulheres que se dedicaram a produção de saberes científicos e ao compartilhamento dos mesmos para camadas específicas da sociedade é possível notar que as narrativas Históricas mantêm seus nomes sob a penumbra. Com frequência nota-se nomes que despontaram no campo das ciências, sob a tutela de companheiros de trabalho ou quando não, capturadas pelo pensamento de círculos masculinos como pais, maridos, irmãos ou qualquer outra figura masculina a subjugar o gênio inventivo feminino em alguma ordem ou sentido.

Até o presente momento poucos são estudos que apontem como as mulheres contribuíram, a partir de viagens cientificas, a pensar uma concepção epistemológica e teórica no Turismo. No que concerne para a formação da História do turismo no Brasil vê-se apenas os homens protagonizando as viagens, e assim abrindo possibilidade para a historiografia do Turismo no Brasil. As viagens dessas duas mulheres e outras, como Maria Graham (1956) que viajou o Brasil no século XIX e em seu diário descreveu o espaço, as interações sociais e outros aspectos, podem dar pistas para entender como a infraestrutura turística do Brasil fora formada. Como importante referência em pesquisas relacionadas as viagens, aos viajantes e o turismo destacam-se obras: Silvio Lima Figueiredo (2010) e de Paulo de Assunção (2012). São leituras importantes, pois, trazem uma discussão de cunho teórico e histórico que engendram pensamentos acerca do viés desses viajantes para pensar o Turismo. Porém, as obras não investigam naquele momento o gênero, enfatizando o papel das mulheres como viajantes. Mas, sugerem a importância de olhar esse ou essa viajante como elemento central no fenômeno turístico (PANOSSO NETTO, 2005).

As referências acerca da História da Ciência são extensas e para esse trabalho escolheu-se algumas. Autoras como Maria Margaret Lopes (2009) desenvolvem argumentos significativos para compreender como a ciência no Brasil se transformou e modificou os espaços de conhecimento no território nacional. E autores com a perspectiva amazônica da ciência destacam-se Nelson Sanjad, este apresenta o MPEG como uma instituição que teve papel importante para o crescimento da ciência na região. Segundo o autor, dois fatos foram significativos: "[...] a visita de Agassiz e a Segunda Exposição Provincial de Produtos Agrícolas e Industriais" (SANJAD, 2010, p. 53). Ao longo da pesquisa teórica da tese, notou-se a significância de pensar a História da Ciência como aporte teórico e epistemológico para compreender o Turismo e seus desdobramentos.

Ao que concerne o Museu Nacional como esfera importante da ciência no sudeste brasileiro enfatiza-se os trabalhos mais atuais de Cecília Ewbank (2018) e Adélia Miglievich-Ribeiro (2019). Essas duas autoras trazem em seus trabalhos investigações sobre o papel do Museu Nacional em diferentes expoentes, como nas pesquisas sobre a museologia e estudos indígenas. Os trabalhos delas refletem pesquisas atuais e auxiliam na compreensão de como a ciência brasileira realizada no Museu Nacional exprime uma ciência que influenciou e ainda sugestiona o campo científico no cenário nacional e amazônico dando ênfase ao trabalho de Heloísa A. Torres, primeira mulher a ser aprovada em concurso público e também gestora do MNRJ.

Estudar as mulheres na ciência e em outras profissões tem sido pauta da tese. E neste artigo o tema torna-se elemento ao debate, tanto para dar base a historiografia das mulheres no campo científico, quanto no estudo do turismo como novas áreas a serem investigadas. Esse dado é fundamental para dimensionar as condutas sociais de uma sociedade patriarcal que, apesar dos avanços dessa metade do século $X X$, ainda fixam linhas e estabelecem os espaços sociais, culturais e científicos em espaços binários, como "espaços masculinos e femininos". E no Turismo também há essa "divisão" entre espaços masculinos e femininos seja no campo mercadológico ${ }^{3}$, como no espaço das viagens e pesquisa na área.

\footnotetext{
${ }^{3}$ Aqui destaca-se o trabalho de Kerley dos S. Alves, onde a autora organiza uma obra interessante acerca do estudo do gênero no Turismo abordando, entre outros artigos, o lugar das mulheres na gerência da hotelaria, o trabalho no turismo e as relações de gênero.
} 
O caminho das mulheres na ciência há tempo vem sendo pesquisado, e destacam-se algumas referências como as de: Sandra Harding (1993), Joan Scott (1995), Margaret Lopes (1998), Gilda Olinto (2011), e mais recentemente, de Mariana Sombrio (2014). Essas autoras escreveram acerca da trajetória de algumas mulheres que se destacaram na composição do cenário científico no Brasil, e no mundo. O caminho feminino na ciência foi cheio de lutas e incertezas com relação a sua participação. Assim como o seu quase desparecimento na História acerca das contribuições da ciência no Brasil, como se notou nas fontes já analisadas com relação à Emília Snethlage e Heloísa Alberto Torres (ALBERTO, SANJAD, 2019).

Tanto Lopes (1998) quanto Sombrio (2014) referenciam as mulheres brasileiras e estas tiveram de enfrentar caminhos cerrados no campo científico. O espaço científico masculinizado não só no Brasil como no mundo, não foi fácil para algumas cientistas, como Bertha Lutz, Aída Hassón-Voloch, Emília Snethlage e Heloísa A. Torres. E outras mulheres que em algum momento de suas carreiras profissionais tiveram de enfrentar obstáculos da sua condição em ser "mulher" em ter de provar sua eficiência cientifica e garantir a perpetuação de sua intelectualidade, e desafiar o patriarcado dentro dos círculos científicos brasileiros no início do século XX.

Com relação ao gênero os novos contextos sociais, culturais, políticos e sexuais pelos quais a chamada "sociedade moderna" vem passando, apresenta-se para esse trabalho a possibilidade de investigar a visibilidade cientifica e histórica da trajetória de vida dessas duas mulheres cientistas do início do século XX, e uma possível relação dessas pesquisas de campo com o Turismo. Elas que possuem interseccionalidades, e segundo Scott (1995) se fazem importantes ao pensar a teoria do gênero a marcar o feminino, tais como: raça, classe social, formação, origens etc. São argumentos importantes a serem discutidos nesse referencial teórico, que inclui as mulheres no Turismo também.

A escolha neste momento da teoria expressada por Scott para compreender o papel das mulheres cientistas é significativa, por apontar essa dualidade entre masculino e feminino. Além disso, também se destaca que essas duas mulheres tinham seus marcadores sociais: eram brancas, de famílias abastadas e de uma elite intelectual naquele momento histórico. Tudo isso acaba por influenciar na configuração dessa mulher que tem a possibilidade de viajar, não somente pelo seu trabalho de pesquisadora, mas por ser uma possível "turista" ao se descolar nos espaços onde realizaram suas explorações de campo.

Essa contextualização inicial é importante, pois sinaliza a configuração de uma teoria nova para pensar as reflexões já escritas e estudas por autores como Figueiredo (2010) e Assunção (2012) acerca do turismo e as viagens. As viagens empreitadas na Amazônia desde o século XVI despontam como marcos históricos importantes, não somente para a história social, política e cultural do Brasil. Mas, pode ser sim elemento para o estudo do turismo. De acordo com Alberto e Pacheco (2020, p. 266) "[...] esses deslocamentos podem ser considerados os primeiros movimentos e experiências pessoais" em que se pode notar a presença de subsídios para refletir sobre a atividade turística. São nessas reflexões que se pode pensar como os indivíduos em busca do novo realizavam essas viagens podendo ser denominadas como "turismo" (PANOSSO NETTO, 2005; TRIGO, 2013) que se compreende nos dias atuais. Um fenômeno sociocultural que se transforma pelas relações interpessoais, de mercado e agora pós-pandemia da Covid-19.

Quando se fala em conceito de viajante devem ser construídos aportes teóricos para melhor trazer quem são essas pessoas, sejam homens e mulheres. E os textos de Bourguet (1997), Dritsas (2005), Lafuente; Lopez-Ocón (1997) e de Leite (1997) são referências fundamentais para traçar esse perfil, a partir da perspectiva da História da Ciência. Para Bourguet e Dritsas os viajantes estavam a serviço da construção da ciência, e de um pensamento eurocêntrico; tinham uma forma de pensar e organizar as viagens, como estudando mapas, por exemplo. As viagens de cunho de construção de redes de conhecimento passam pelas concepções desses autores, e as mulheres também chegaram 
a ocupar esses papeis de estarem envolvidas em viagens de pesquisa cientifica de regiões ainda não exploradas em várias partes do mundo.

Em leituras de Trigo (2013) e Panosso Netto (2005) as viagens são elementos conceituais que influenciam a imaginação humana desde tempos imemoriais. Os deslocamentos humanos configuravam-se pela busca de novos espaços para viver, a busca por alimentos, e em locais para proteção pessoal e coletiva. Mas, esse mover-se ao encontro de outros espaços e de novas pessoas também levou a novas formas de conhecimento humano. Assim afirma Trigo (2013, p. 22): "Foi justamente a vontade de conhecer, de aventurar-se por este mundo que forjou no ser humano desejo pelas viagens". E concluem Alberto e Pacheco que "[...] as primeiras viagens na Amazônia que se configuram como um plano de conhecimento do espaço, seja natural e social, coaduna-se com as discussões centrais de que o conceito moderno de ciência e de turismo estão engajados ao tema do pensamento abissal" (2020, p. 271).

Essa discussão entre o viajante e a viagem também suscita um debate que tem avançado ao longo dos anos e ganhado espaço em esferas que investigam o Turismo e a Ciência. A pesquisa em âmbito de epistemologia surge em discussões realizadas por Moesch (2002), quando essa autora expõe importantes questões de como olhar a cientificidade que há no fenômeno turístico. A análise do fazer-saber do turismo para o saber-fazer é uma investigação significativa que aponta para as viagens dessas mulheres, como possibilidades desse olhar para a atividade turística de outra forma. No caso da História, por exemplo, abraçando um campo inter e transdisciplinar, também defendida por essa autora.

As investigações mais recentes de Moesch e Beni (2015) produzem um debate que procura dialogar com essa cientificidade que permeia o estudo do turismo. Tendo como questões algumas teorias e conceitos que podem ser analisados e trazidos para estudos como esse, entre História da Ciência e do Gênero. E essas disciplinas podem ser refletidas como vieses a possibilitar o Turismo a um lugar no campo da ciência. São nessas investigações que esse artigo, através da História e por meio das viagens dessas cientistas, pode trazer mais um complemento a pensar esse fenômeno social, como expõe Panosso Netto (2005), como possível campo para ampliar essa discussão epistemológica que envolve as viagens e o turismo.

Este artigo é uma possibilidade de pensar essa investigação que congrega o estudo do Turismo com as relações de Gênero e a Ciência. Acredita-se que essas reflexões iniciais possam abrir possibilidades de novas teorias acerca do pensar o Turismo e suas afinidades com outras disciplinas como a História e o Gênero.

\section{Emília Snethlage e Heloísa Alberto Torres: duas cientistas na Amazônia}

Este trabalho tem como ponto também apresentar que as mulheres tiveram um papel fundamental na ciência que hoje se faz no Brasil, e na Amazônia. Uma ornitóloga e uma antropóloga deixaram um legado importante para que mulheres, inclusive turismólogas pudessem estar produzindo e pesquisando em campo nos dias de hoje. A história de Emília Snethlage se confunde com a história do Museu Paraense Emílio Goeldi. Instituição essa que desde 1866 produz ciência na região amazônica. Com relação a Heloísa Alberto Torres, esta também está ligada intimamente com o Museu Nacional do Rio do Janeiro. Espaço científico que foi a base para o Brasil tornar-se um território para pensar e produzir ciência nas áreas das ciências naturais, etnológicas e museais.

Com sua espingarda Flaubert na mão, o suor no rosto e a visão atenta na paisagem, esperava com paciência suas aves. Assim era a ornitóloga Emília Snethlage (1868-1929) em campo, ver Figura 1 a seguir. Destemida, descrevia um de seus biógrafos, o 
pesquisador Osvaldo Rodrigues da Cunha (1989) do Museu Paraense Emílio Goeldi ${ }^{4}$. Uma mulher estrangeira na Amazônia construindo o caminho da ciência, que culminaria na produção de seu trabalho mais importante na região: o Catálogo de Aves Amazônicas (JUNGHANS, 2011).

Figura 1 - Emília Snethlage no Museu Goeldi, início do século XX

Fonte: Site do Museu Goeldi www.museu-goeldi.br (2018). Acervo Fotográfico.

Um de seus principais biógrafos é Emil-Heinrich Snethlage (1930), seu sobrinho. Entre outros estão Osvaldo Cunha (1989), Miriam Junghans (2011 e 2016) e Nelson Sanjad (2013; 2019). Eles trazem aspectos de Emília no campo profissional e, bem discretamente no campo pessoal dessa alemã moradora dos trópicos amazônicos por 17 anos. É interessante notar três homens e uma mulher a escrever acerca de Snethlage. Espera-se revelar ao longo desse breve trabalho um pouco de sua vida profissional, a contribuição que Emília Snethlage deixou para as ciências naturais no Brasil, no exterior, e principalmente para a Amazônia.

Assim E.-Heirinch Snethlage escreve no obituário: "Ela, que partiu de modo tão repentino, foi dada à luz em 13 de abril de 1868, em Kraatz, Gransee (Mark Brandenburg), a segunda de quatro irmãos. Seus pais eram o pastor de aldeia Emil Snethlage e D. Elisabeth, nascida Rosenfeld" (1930, p. 123). E continua:

Não Ihe causou surpresa ver a pequena filha dando conta de todas as matérias da formação humanística em voga na época, junto com seu irmão, um ano mais velho, às vezes até levando vantagem em relação a este. O primeiro estímulo à

\footnotetext{
${ }^{4}$ Fundado em 1866 como Museu Paraense, somente 1894 com a reformulação do suíço Emílio Goeldi, que a instituição inicia suas atividades cientificas e denominado Museu Paraense de História Natural e Etnografia, e atualmente Museu Paraense Emílio Goeldi (SANJAD, 2010).
} 
sua paixão pela natureza se deve ao livro "Entdeckungsreisen in Feld und Flur" [Jornadas de descoberta em campos e campinas], de Hermann Wagner, que, com sete anos de idade, ela lia e relia repetidas vezes.

Esse texto é um pouco da vida de Emília, que chegou ao Brasil em 1905. Para ocupar a vaga na seção de zoologia do Museu Paraense de História Natural e Etnografia. Uma Doutora para a Amazônia.

Emília Snethlage chegou com a missão de pesquisar as aves amazônicas. Mas, ela fez mais que pesquisas ornitológicas. Emília entrou em estudos relacionados com a botânica, outras espécies de animais, como estudos de peixes e até as primeiras investigações etnográficas com populações indígenas na região. Em Alberto e Sanjad (2019, p. 1048) é possível ver um pouco de sua trajetória como segue:

A missão que recebeu em Belém foi estudar as aves da região, mas seu papel como cientista extrapolou suas atividades imediatas, deixando-nos um significativo legado cultural, principalmente às mulheres, que ainda buscam se firmar em campos profissionais tradicionalmente masculinos, como o científico. Apesar de viver em uma época na qual as mulheres ainda estavam a ampliar seu espaço na sociedade, em pouco tempo Emília despontou como uma das mais importantes cientistas do Brasil.

Dessa maneira, Dra. Emília deixa um caminho importante para a ciência, e pode-se aventar também novos olhares que se pode empreender ao Turismo. A reflexão sobre a trajetória profissional de uma cientista com a perspectiva de uma ciência foi feita por mulheres, também permite ao Turismo pode ter contribuições significativas na compreensão das viagens e do próprio construto da investigação e da dinâmica da atividade turística.

E as viagens continuam a despertar o conhecimento, assim de Belém do Pará parte-se para o Rio de Janeiro ainda no início do século XX. Apresenta-se Heloísa Alberto Torres (1895-1977), ver Figura 2 a seguir. Uma antropóloga e a primeira mulher a dirigir o Museu Nacional do Rio de Janeiro na década de 1930. Uma mulher cientista que formou os primeiros antropólogos no Brasil, entre eles Eduardo Galvão5. Uma mulher que esteve intimamente ligada na formação intelectual das Ciências Sociais e da antropologia brasileira (MIGLIEVICH-RIBEIRO, 2015).

Figura 2 - Heloísa Alberto Torres em retrato

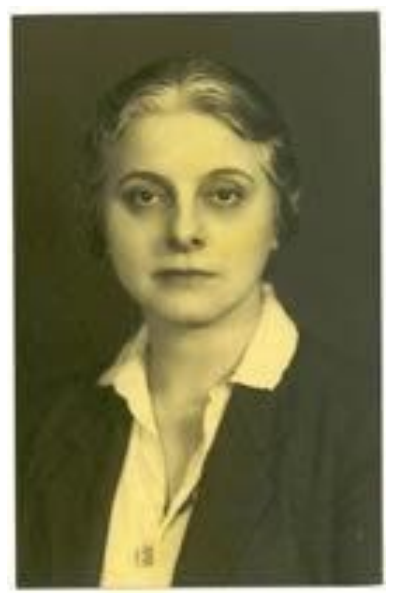

Fonte: Site do Blog “Casa de Cultura Heloísa Alberto Torres”

\footnotetext{
${ }^{5}$ Eduardo Galvão foi primeiro pesquisador a ter o título de Antropólogo de formação. Ele foi aluno de Charles Wagley, este norte-americano foi "aluno" de Heloísa Alberto Torres no Brasil. (CORREA, 2008)
} 
Essa carioca, nascida em Itaboraí (RJ) filha de uma família da elite social, teve mais dois irmãos e desde cedo também teve acesso a leitura e a um campo cultural diverso. Seu pai Alberto Torres, foi importante figura no cenário político nacional e intelectual do fim do século XIX. A influência dele ficou em Heloísa, pela sua eloquência e na maneira de entender a educação e a cultura como caminhos possíveis para a transformação da sociedade.

Em 1925 duas notas de jornais da cidade do Rio de Janeiro chamam a atenção por trazer como título as seguintes frases: "Mais uma victoria do feminismo [...]", esta é uma nota do Jornal Correio da Manhã. E outro texto de jornal traz: "Uma victoria que faz honra ao feminismo brasileiro [...] a que concorreram vários candidatos, a senhorita Alberto Torres (grifo nosso) conquistou brilhantemente, conforme noticiamos hontem, o primeiro logar"'. Olhar essas notícias fazem pensar em um importante evento onde as mulheres puderam alcançar um notável prêmio ou algo parecido. E assim, a trajetória profissional e cientifica de Heloísa A. Torres foi sendo construída. Seu universo científico era permeado pela presença masculina. Mas, isso não renegou seu papel, enquanto mulher cientista, em toda sua herança deixada para as ciências sociais brasileira. Pelo contrário, assim como Emília, Heloísa sabia do seu lugar no Museu Nacional e da sua importância para a ciência brasileira.

E sua viagem ao Marajó em 1930 para estudar os campos arqueológicos e arte cerâmica foi o marco em sua carreira. Uma viagem que desenhou o seu "cartão de visita" para esta recém professora aprovada no concurso do Museu Nacional para os caminhos na antropologia brasileira (MIGLIEVICH-RIBEIRO, 2015). Em texto de Mariza Corrêa (2003) "Dona Heloísa e a pesquisa de campo" chama atenção pelo título trazer "Dona", e parece ser mais que uma adjetivação de respeito a alguém com mais idade. O "Dona" de fato tinha uma dona: Heloísa Alberto Torres. Mulher, intelectual, filha de um político e intelectual que marcou a história da Antropologia no Brasil. Mas, que pouco aparece na "história oficial" dos estudos sobre os desdobramentos em que se colocam a História da Ciência no Brasil, e seus desdobramentos como as pesquisas sobre os indígenas, sobre o patrimônio histórico brasileiro.

Para este trabalho o enfoque é sua viagem ao Marajó. Uma de suas biografas Adélia Miglievich-Ribeiro (2015) apresenta como a expedição ao Marajó marcou a vida profissional de Heloísa. Seu trabalho foi reconhecido em âmbito nacional. A cerâmica marajoara tornou-se elemento importante da pesquisa sobre as populações indígenas amazônicas. $E$ assim como Emília, a viagem de Heloísa tem características importantes a serem analisadas, tendo como o foco os estudos sobre o Turismo.

O estudo da ciência, das mulheres e das viagens ao longo da investigação da tese e que oferece bases para este artigo tem se mostrado promissor para novas perspectivas para pesquisar o Turismo. A investigação no campo da História tem possibilitado olhar essas três vertentes como caminhos novos a pensar o campo interdisciplinar que a atividade turística possui. Assim, este trabalho é um começo para essas reflexões.

As viagens empreendidas por essas duas mulheres em pleno começo do século $\mathrm{XX}$ de fato foi um marco para a ciência no Brasil. Foram feitos que homens pesquisadores ainda não tinham realizado. Como a travessia que Emília Snethlage fez do Xingu ao Tapajós (1909) e a viagem aos campos do arquipélago do Marajó (1930) por Heloísa A. Torres. Nessas excursões pode-se ver elementos que são alinhados com os subsídios que caracterizam as viagens turísticas. Será discutido mais à frente no item dos resultados e discussões.

\section{Metodologia}

${ }_{7}^{6}$ Fonte da Biblioteca Nacional Digital, Acervo Hemeroteca Digital $(2018,2019)$.

${ }^{7}$ Fonte da Biblioteca Nacional Digital, Acervo Hemeroteca Digital $(2018,2019)$. 
O processo metodológico para este artigo é pautado nas orientações dentro da História, ou seja, o campo aqui são as fontes históricas que trazem pistas e indícios (GINZBURG, 2006) que oferecem uma visão da vida profissional dessas duas cientistas e as viagens empreendidas por elas. As fontes deverão indicar até onde a pesquisadora e o pesquisador devem construir o seu trabalho histórico, e aqui adaptado as ciências sociais aplicadas, que é o Turismo.

$\mathrm{Na}$ História quanto maior o volume empírico de fontes mais perto do fato se chega. Assim, os recortes de jornais, relatórios e livros escritos por elas e suas cartas formam um arcabouço importante para entender um pouco desse universo onde Emília e Heloisa vivenciaram ao realizar suas viagens de campo. Assim, referências como de Carla Pinsky (2008) fornecem, até o momento, um caminho para pensar a utilização de fontes de forma organizada e que possa trazer o maior número de verdades/fatos acerca da vida dessas cientistas que são Emília Snethlage e Heloisa A. Torres.

O primeiro passo realizado para a tese, e que reflete na construção desse trabalho foi colher o maior número de fontes. Estas em meios impressos e digitais em sites como da Biblioteca Nacional Digital e no Arquivo Nacional do Rio de Janeiro desde ano de 2018. A partir da tese pôde-se organizar as fontes em três áreas: recortes de jornais do período de 1905 a 1930 para a investigação tanto da trajetória de Emília Snethlage quanto de Heloísa A. Torres. Este recorte temporal justifica-se, pois, o foi período de chegada de Emília Snethlage em Belém, e a viagem empreendida por Heloísa Alberto Torres ao Marajó, como já explicado anteriormente.

Os jornais são, principalmente, do Rio de Janeiro, São Paulo, Pará e Amazonas. Nessas notas encontram-se, em geral, materiais sobre as expedições que elas fizeram, a divulgação de suas pesquisas na região Amazônica, especificamente no Xingu, Tapajós e o arquipélago do Marajó relevando o recorte espacial para este artigo. Esses documentos estão, em sua maioria digitalizados no acervo da Hemeroteca da Biblioteca Nacional Digital. A pesquisa iniciou em março de 2018 até o presente momento da escrita desse trabalho. Que em virtude da pandemia da Covid-19 foi interrompida a pesquisa de campo ao Rio de Janeiro em 2020 devido a limitação de viagens em território nacional e ao fechamento dos espaços públicos, entre eles bibliotecas e arquivos.

Antes da interferência pandêmica também foram realizadas pesquisas em campo no Museu Paraense Emílio Goeldi. Na biblioteca Domingos Soares Ferreira Penna que possui acervo importante sobre a produção cientifica na região amazônica, e no Arquivo Guilherme De La Penha. Neste constam importantes fontes sobre Emília Snethlage, como cartas institucionais e pessoais, além da documentação da gestão realizada por Snethlage. Esses documentos em grande parte estão impressos e foram lidos, fichados e interpretados à luz da História. E dessa maneira, a pesquisa está sendo realizada para a tese e foi para este artigo.

Outro tipo de fonte importante são os documentos sobre o funcionalismo público federal do início do século $X X^{8}$ onde se vê suas funções e cargos que servidores federais exerceram tanto no Museu Goeldi, quanto no Museu Nacional. Também em campo nos arquivos de instituições de pesquisa, encontrei cartas pessoais e institucionais ${ }^{9}$, tanto de Emília como de Heloísa. Romances em que elas inspiraram personagens, vendo assim outras facetas dessas mulheres e que auxiliaram a entender suas viagens de campo.

E suas produções também foram fontes importantes para que se pudesse conhecer seus trabalhos. Assim, as suas obras, como relatórios científicos e livros são chaves importantes para abrir oportunidades para compreender seus papeis de cientistas e quais

\footnotetext{
${ }^{8}$ Pesquisa digital realizada em 2018 e 2019 nos sites da Biblioteca Nacional Digital (https://bndigital.bn.gov.br/), e site do Arquivo Nacional (http://sian.an.gov.br/sianex) do Rio de Janeiro.

${ }_{9}$ Pesquisa de campo no Museu Paraense Emílio Goeldi, com a orientação do professor Nelson Sanjad, que atualmente cuida do acervo sobre Emília Snethlage, também iniciada em 2018.
} 
os caminhos, teorias e estudos que elas fizeram para que realizassem suas viagens de campo. O campo de pesquisa na História e o objeto de pesquisa estão nas documentações disponíveis.

Com relação a revisão bibliográfica esse trabalho tem bases na História da Ciência e a Micro-história como teorias basilares no campo Historiográfico. No Turismo as leituras acerca das viagens e do turismo, e da História do turismo no Brasil construíram a discussão acima acerca da noção de como as viagens dessas mulheres apontaram para a investigação turística. E por fim, a metodologia pautou-se em artigos, livros, teses, dissertações escritas por autores e autoras sobre suas vidas e carreiras científicas de Emília Snethlage e Heloísa A. Torres.

\section{Resultados e discussões preliminares}

Nos resultados preliminares até o presente momento têm-se que as viagens dessas mulheres cientistas contaram com elementos que hoje entende-se como equipamentos turísticos, tais como: hospedagem, transportes, alimentação, redes de guias. Nas fontes foram possíveis perceber que tanto a viagem de Emília Snethlage feita em 1909 entre o Xingu e o Tapajós e a viagem de Heloísa Alberto Torres ao Marajó em 1930 imprimem elementos que podem ser vistos como equipamentos turísticos. Para isso trazer as fontes torna-se importante para analisar essas afirmações.

Em 1909 Emília Snethlage fez a viagem, que não tinha sido feita por nenhum outro pesquisador, entre o Xingu e o Tapajós (SNETHALGE, 1912) e nela há indícios de como uma viajante se preparava, se organizava e realizava uma viagem. A narrativa conta com detalhes sobre a preparação da viagem, contatos a serem realizados, locais onde deveriam passar, se hospedar. O que estava sendo feito, as pesquisas e anotações tanto da parte cientifica como de alguns momentos mais pessoais dela. São nesses indícios, como expõe Ginzburg (2006) que se encontram os primeiros passos dessa possível "turista" na Amazônia.

Na nota seguinte tem-se como foi o começo da viagem de Emília:

Tendo conseguido em Santarém o apoio da importante casa de commercio dos Snrs. Souza e Braga, concedido com a maior amabilidade, parti da capital a 11 de outubro de 1908 e cheguei a 19 do mesmo mez ao ponto terminal da navegação a vapor no Rio Tapajoz ao pé da primeira cachoeira. Aqui tive a ventura de encontrar o Sr. Coronel Raymundo Brazil, prefeito do alto Tapajoz e proprietário não só da maior parte dos seringaes do médio Tapajoz como também do baixo Jamauchim. (SNETHLAGE, 1912, p. 49-50) ${ }^{10}$.

Para a investigação no turismo, essas fontes oferecem importantes referências para analisar essas viagens e começar a pensá-las em nova perspectiva teórica, como já apontada por Figueiredo (2010) e Assunção (2012), mas que trazem mulheres como protagonistas desses deslocamentos. São apontamentos iniciais, mas que podem ao final da tese sugerir debates mais profundos acerca do tema da relação das primeiras viagens feitas por mulheres cientistas e o estudo do Turismo.

Em outro trecho no relatório de Snethlage (1912) destacam-se dois pontos importantes para equiparar suas narrativas a uma possível investigação com o Turismo. São os destaques para a hospedagem e para a alimentação. Tem-se o texto:

Demorámos um dia inteiro na Cachoeira grande para esperar as canoas de Sta. Julia, e poude então admirar à vontade a paizagem grandiosa que se extende ao pé do monticulo onde tínhamos estabelecido o nosso acampamento. [...] Do outro lado do rio existia uma roça, não visível da agua, cujos produetos principaes eram

\footnotetext{
${ }^{10}$ A grafia do texto é original da fonte
} 
mandioca, bananas e milho. Os índios comem as bananas maduras em forma de mingau ou verdes e fritas; achei a estas últimas um gosto de pão. Eram bananas, alem de peixe, a sua comida principal n'este tempo, a mandioca ainda não estando madura. (p. 54; 69).

São com esses elementos históricos que o Turismo pode ter um novo aporte, para vislumbrar um caminho mais livre na sua investida como uma possível nova ciência.

Como aponta o historiador Ginzburg (2006) esses sinais da história da vida profissional de Snethlage pode contribuir para a formação de uma nova visão epistemológica acerca das viagens turísticas. $\mathrm{O}$ adentrar em um novo universo acadêmico como da História, tem apontado possibilidades de olhar a teoria do Turismo de outra forma. Essas viagens, feitas por essas mulheres pode trazer um novo pensar, e saber-fazer (MOESCH, 2002) acerca do entendimento do movimento que as viagens exerceram para a formação do estudo da atividade turística. As crises enfrentadas, não somente pelo Turismo, mas pela própria história com relação a sua formação cientifica denotam discussões como a deste artigo.

Ao retomar o texto de Moesch e Beni (2015) as visões que possuem um classicismo teórico quanto as investigações do turismo estão sendo pautadas nessas novas frentes de pesquisas. Esse artigo, por exemplo, procura dar uma nova visibilidade, por meio da historiografia, de como intervir em inquirições ainda não vistas na análise do Turismo. Pautadas nesse caminho da ciência, esse novo olhar sobre a dinâmica da atividade turística sugere um avanço nas suas linhas teóricas e conceituais.

Outro resultado a ser analisado é o do próprio estudo da região Amazônica. Que também necessita de uma investigação ampliada no que se refere a pesquisa em Turismo. Interessante notar como essas investigações aproximam-se de compreender como a região foi averiguada por elas, e que auxiliam a entender a dinâmica socioespacial da Amazônia. Como a região historicamente há anos tem sido alvo de viagens e explorações, o Turismo também deve ter espaço nesses círculos de conhecimento históricos, sociais, econômicos e culturais.

$\mathrm{Na}$ viagem feita por Heloísa A. Torres para o Marajó em 1930 sua narrativa tem um tom mais pessoal, mas que aponta vestígios de como uma viajante, e possível "turista" sentia-se naquele local. Espaço que é contado/narrado por muitos e algumas viajantes como local "exótico". Deve-se enfatizar nessa discussão que o imaginário amazônico atraia, e ainda convida olhares de diversas áreas do conhecimento. E estudos como os de Mccormack (2017) ajudam a compreender como a relação do contato entre viajantes e a sociedade local formou redes de conhecimento sociais, culturais e científicos, por meio de viajantes, em destaque Alfred Russel Wallace e Alexandre Von Humboldt.

Heloísa ao estar no Marajó, destaca Miglievich-Ribeiro (2015), escreve que a pesquisadora narra em seu diário de campo ${ }^{11}$ diversas anotações sobre de onde iria estar, inscrições de desenhos e mapas, passando pela escrita de expressões idiomáticas das populações ali viventes. Mesmo com um toque pessoal, sua descrição do local é interessante, e que supõe a refletir o olhar de "uma turista", como se tem a seguir:

Chaves - Marajó (28/9/1930), Minha mamãe, A tua heroica filha tem andado a cavalo que não é vida. A primeira vez - foi na Mexiana - andei $4 \frac{1}{2} \mathrm{~h}$, dormi numa fazenda e, no dia seguinte, montei às $5 \mathrm{~h}$ da manhã para fazer outro tanto! [...] Cheguei ontem de Ananatuba, mais para o centro, onde passei nove dias, trabalhei bastante e com proveito. Cheguei ontem de manhã à fazenda e parto hoje à noite de barco para a Fazenda Montenegro (p. 61).

\footnotetext{
${ }^{11}$ Até o presente momento desse artigo e tese em andamento a autora não conseguiu ter contato com esse material, que se encontra no Rio de Janeiro.
} 
De fato, uma pesquisadora, mas também uma possível viajante e/ou uma "turista científica"? São com essas questões e com esses elementos acredita-se que essas narrativas e pesquisas dessas cientistas ampliem possibilidades contemporâneas para 0 estudo do Turismo.

Esses resultados são preliminares e enfatizam alguns dos pontos a refletir essas novas oportunidades de investigação na dinâmica no Turismo. Os resultados não estão fechados, devido a continuidade da tese. $E$ isso fortalece o prosseguir dessas pesquisas. As fontes históricas, como as cartas e os relatórios apontam como essas viagens além de científicas, vislumbraram a compreensão de como a História e o Turismo podem unir-se enquanto disciplinas para se entender como a atividade turística pode ser pensada em uma nova episteme de conhecimento, e assim alargar as teorias e conceitos já vigentes sobre a área.

\section{Conclusão}

Esses preâmbulos teóricos são alguns dos pontos que refletem como a investigação no Turismo tem sido ampliada. Professoras (es) e pesquisadoras (es) têm buscado em outras áreas afins movimentos conceituais que estão auxiliando na formação de uma proposição e métodos para a pesquisa na atividade turísticas. Essa busca por uma nova episteme do turismo impulsiona trabalhos como esse, que investigam contextos e pessoas em um determinado tempo histórico e social.

As mulheres e a ciência têm sido um assunto que tem ganhado espaço, principalmente, na Antropologia, na História, e com a pesquisa de doutorado em andamento pode-se até pensar no Turismo. Essas discussões de quanto a mulher foi e, sugere-se que, ainda é invisibilizada na sociedade atual, ganha ecos em espaços na dinâmica da investigação acerca do Turismo. A História da Ciência no Brasil não pode deixar de celebrar nomes como Emília Snethlage e Heloísa Alberto Torres, pois elas foram cientistas que enfrentaram lutas e adversidades para estarem e se manterem em um universo masculino que era, e ainda é a ciência.

A história de vida de Emília Snethlage desponta como vertente importante para a História da Ciência na Amazônia paraense. A contribuição de seu trabalho, enquanto pesquisadora e gestora da mais importante instituição científica da região amazônica, no Museu Goeldi demonstra o quanto as mulheres fizeram parte do contexto científico nessa região. Suas pesquisas alcançaram o Brasil e o exterior. Ela foi uma cientista que deixou elementos significativos para o debate do feminino na ciência. $E$ as suas viagens foram como "pistas" que esse artigo trouxe para se refletir o "turismo moderno" na Amazônia e no Brasil.

E o legado de Heloísa Alberto Torres também está no mesmo patamar. Essa mulher cientista formou os primeiros antropólogos brasileiros. Seu trabalho de conhecimento na área da cerâmica marajoara ainda é canônico nas investigações sobre o tema. Além de ter sido uma pesquisadora de campo, sua marca ficou mais bem registrada na gestão do Museu Nacional do Rio de Janeiro. Primeira mulher a dirigir a instituição e a obra de Heloísa ultrapassou a viagem que empreendeu no Marajó. Ela esteve envolvida em pauta cientificas importantes como no patrimônio brasileiro, por do Instituto do Patrimônio, Histórico, Artístico e Nacional - IPHAN e das primeiras investigações com as populações indígenas, por meio do Serviço de Proteção do Índio, logo depois denominada Fundação Nacional do Índio FUNAI.

E por fim esse trabalho deixa mais questões do que respostas, porque a investigação da tese acerca das mulheres cientistas continua. Esse artigo é apenas um recorte desse universo de investigação que possui muitas portas a serem abertas para o 
debate na atividade turística. As buscas por espaços teóricos e conceituais ainda não vistos por pesquisadoras (es) do Turismo são amplos, e a investigação na área da História tem sido um deles. A inquirição por meio de fontes, como cartas, jornais e outros documentos históricos abriram oportunidades de expandir os aspectos metodológicos e teórico-conceituais do Turismo atual, e assim a pensar esse tema.

\section{Referências}

ALBERTO, Diana P. Sá; PACHECO, Agenor Sarraf. Viagens Cientificas, Gênero e Turismo: análise da travessia de Emília Snethlage do Xingu ao Tapajós em 1909. ALVES, Kerley S. (Org.). Diálogos Sociais em Turismo: elementos hegemônicos e contra hegemônicos. Belo Horizonte: Editora Dialética, 2020, p. 265-280.

ALBERTO, Diana; SANJAD, Nelson. Emília Snethlage (1868-1929) e as razões para comemorar os 150 anos de nascimento. Bol. Mus. Para. Emílio Goeldi. Cienc. Hum., Belém, v. 14, n. 3, p. 1047-1070, 2019.

ASSUNÇÃO, Paulo de. História do Turismo no Brasil entre os séculos $\mathbf{X V I}$ e $\mathbf{X X}$ viagens, espaço e cultura. Barueri, SP: Manole, 2012.

BENI, Mario Carlos; MOESCH, Marutschka Martini. A teoria da complexidade e o ecossistema do turismo. Turismo - Visão e Ação, Balneário Camboriú, v. 19, n. 3, p. 430-457, 2017. Disponível em: < https://dx.doi.org/10.14210/rtva.v19n3.p430-457 > DOI: 10.14210/rtva.v19n3.p430-457.

BIBLIOTECA Digital Nacional. Acervo da Hemeroteca. Rio de Janeiro: Biblioteca Nacional, 2018-2019. (Digital (https://bndigital.bn.gov.br/).

BOURGUET, Marie-Noëlle. O Explorador. In: VOVELLE, M. (Dir.). O Homem do Iluminismo. Lisboa: Presença, 1997, p. 207-249.

CORRÊA, Mariza; MELLO, Januária (Orgs.). Querida Heloísa/ Dear Heloísa - cartas de campo para Heloísa Alberto Torres. Núcleo de Estudos de Gênero - PAGU. São Paulo: UNICAMP, 2008.

Dona Heloísa e a pesquisa de campo. Antropólogas \& Antropologia. Belo Horizonte: Editora da UFMG, 2003.

CUNHA, Osvaldo Rodrigues da. Maria Elizabeth Emília Snethlage. In: CUNHA, O. R. Talento e Atitude: estudos biográficos do Museu Emílio Goeldi, 1, Belém: Museu Paraense Emílio Goeldi, 1989, p. 83-102.

DRITSAS, Lawrence. From Lake Nyassa to Philadelphia: a geography of the Zambesi Expedition, 1858-64. The British Journal for the History of Science, v. 38, n. 1, p. 35-52, 2005.

EWBANK, Cecilia de Oliveira. Antropólogos, curadores de museus e museografia durante a gestão de Heloísa Alberto Torres no Museu Nacional (1938-1955). Revista MUSAS, n. 8, p. 8-22, 2018.

FIGUEIREDO, Silvio L. Viagens \& Viajantes. São Paulo: Annablume, 2010.

GINZBURG, Carlo. 0 queijo e os vermes - o cotidiano e as ideias de moleiro perseguido pela Inquisição. São Paulo: Companhia das Letras, 2006.

GRAHAM, Maria. Diário de uma viagem ao Brasil - E de uma estada nesse país durante parte dos anos de 1821, 1822 e 1823. São Paulo: Companhia Editorial Nacional, 1956.

HARDING, Sandra. A instabilidade das categorias analíticas na teoria feminista. Revista Feminista. n.1, p. 7-31, 1993. 
JUNGHANS, Miriam. Among Birds and Net(Work)S: Material and Social Practices in the Trajectory of Ornithologist Emilie Snethlage (1868-1929). HoST History of Science and Technology, v. 10, p. 71-101, 2016.

Abrindo as gavetas: Emília Snethlage (1868-1929) e as coleções ornitológicas do Museu Goeldi e do Museu Nacional do Rio de Janeiro em 1922. In: LOPES, M. M.; HEIZER, A. (Orgs.). Colecionismos, práticas de campo e representações. Campina Grande: EdUEPB, 2011. p. 61-73.

LAFUENTE, Antonio; LÓPEZ-OCÓN, Leoncio. Tradiciones científicas y expediciones ilustradas en la América hispana del siglo XVIII. In: SALDAÑA, J. J. (Coord.). Historia social de las ciencias en América Latina. Cidade do México: UNAM/Miguel Ángel Porrua, 1996, p. 247-281.

LEITE, Miriam L. M. Viajantes naturalistas - caracterização. In: LEITE, M. L. M. Livros de Viagem (1803-1900). Rio de Janeiro: UFRJ, 1997, p. 161-198.

LOPES, Maria Margaret. "Aventureiras" nas ciências: refletindo sobre gênero e história das ciências naturais no Brasil. Cadernos Pagu. n. 10, p. 345-368, 1998.

O Brasil descobre a Pesquisa Científica: Os Museus e as Ciências Naturais no Século XIX. 2 ed. São Paulo: Editora Hucitec/Editora Unb, 2009.

MCCORMACK, Carey. Collection and Discovery: Indigenous Guides and Alfred Russel Wallace in Southeast Asia, 1854-1862. Journal of Indian Ocean World Studies, v. 1, p. 110-127, 2017.

MIGLIEVICH-RIBEIRO, Adélia. Heloisa Alberto Torres e Marina de Vasconcelos pioneiras na formação das ciências sociais no Rio de Janeiro. Rio de Janeiro: Editora da UFRJ, 2015.

MIGLIEVICH-RIBEIRO, Adélia. Revisitando o Museu Nacional e a História da Antropologia no Brasil pelas mãos de Heloísa Alberto Torres. Rev. Política \& Sociedade, v. 18, n. 41, p. 27-59, 2019.

MOESCH, Marutschka Martini; BENI, Mário Carlos. Do discurso sobre a ciência do turismo para a ciência do turismo. Anais.. São Paulo: ANPTUR, 2015.Disponível em: < https://www.anptur.org.br/anais/anais/files/12/48.pdf>.

OLINTO, Gilda. A inclusão das mulheres nas carreiras de ciência e tecnologia no Brasil. Inc. Soc., Brasília, DF, v. 5 n. 1, p.68-77, jul./dez. 2011.

PANOSSO NETTO, Alexandre. Filosofia do Turismo - Teoria e epistemologia. São Paulo: Aleph, 2005.

PINSKY, Carla B. (Org.). Fontes históricas. 2 ed. São Paulo: Contexto, 2008.

SANJAD, Nelson. A coruja de Minerva - O Museu Paraense entre o Império e a República (1866-1907). Brasilia: Instituto Brasileiro de Museus; Belém: Museu Paraense Emílio Goeldi; Rio de Janeiro: Fundação Oswaldo Cruz, 2010.

et al. Emília Snethlage (1868-1929): um inédito relato de viagem ao rio Tocantins e o obituário de Emil-Heinrich Snethlage. Bol. Mus. Para. Emílio Goeldi. Cienc. Hum, Belém, v. 8, n. 1, p. 195-221, 2013.

SCOTT, Joan. Gênero: uma categoria útil de análise histórica. Educação \& Realidade, Porto Alegre, v. 20, n. 2, p. 71-99, jul/dez, 1995.

SNETHLAGE, E.-Heinrich. Dr. Emilie Snethlage zum Gedächtnis. Journal für Ornithologie, v. 78, n. 1, p. 123-134, 1930. Tradução de João Batista Poça da Silva.

SNETHLAGE, Emília. Travessia entre o Xingu e o Tapajós. Boletim do Museu Goeldi, Belém, vol. XII, S. 49-92, 1912. 
TRIGO, Luiz G. Godoi. A Viagem - caminho e experiência. São Paulo: Aleph, 2013. 